\title{
ETIOLOGY OF DIABETIC FOOT INFECTION IN PATIENTS WITH POORLY CONTROLLED DIABETES
}

\author{
Sergey D. Iliev, \\ Lyubomir Ts. Beshev, \\ Kiril L. Nedyalkov, \\ Dobromir D. Nguen', \\ Valentina E. Edreva-Besheva, \\ Mariya P. Sredkova ${ }^{2}$, \\ Yuliya M. Belcheva ${ }^{1}$, \\ Emiliya J. Dimitrova ${ }^{1}$
}

\author{
Department of Surgery, \\ Medical University - Pleven \\ ${ }^{1}$ Clinical Microbiology Study Group, \\ Medical University - Pleven \\ ${ }^{2}$ Department of Microbiology and \\ Medical Genetics, \\ Medical University - Pleven
}

\begin{abstract}
Summary
The aim of the study was to define the spectrum and susceptibility of microorganisms, isolated from diabetic foot ulcers in patients with poorly controlled diabetes, treated at the clinic of surgery, and compare microbial findings of specimens collected superficially and from deep tissues. The study included 19 patients with type 1 and 2 diabetes with clinical signs of infection. All patients were with poorly controlled diabetes and staged from 3rd to 5 th grade according to the Wagner diabetic foot scale. Swab samples from non-debrided wounds and biopsy samples from deep tissues were collected from each patient. Specimens were inoculated on media for isolation of aerobic and anaerobic bacteria. Identification and susceptibility testing of the isolated organisms were performed by conventional methods, and VITEK 2 and mini API Systems (bioMerieux, France). A total of 88 bacterial isolates were cultured, comprising 56 clinical strains. Gram positive bacteria were the most common isolated organisms (53.57\%), followed by Gram negative bacteria (26.78\%) and anaerobic bacteria (19.64\%). Staphylococcus aureus was the most common organism detected (10 strains), followed by Enterococcus spp. (7 strains), Escherichia coli (7 strains), Bacteroides spp. (6 strains) and various other organisms of low incidence. Polymicrobial infection was detected in 17 (89.47\%) of the patients. In most of the cases infections were caused by 3 bacterial species. Mixed aerobic/anaerobic infections were detected in 9 (47.3\%) patients. In 15 (78.94\%) patients, there was a coincidence of bacterial findings from superficial and deep tissue samples. The strains isolated were susceptible to commonly used antimicrobials for treatment of diabetic foot infection. The predominant part of the diabetic foot infections were polymicrobial, caused by association between two or three microbial species. In half of the cases the infection was mixed. There was a good correlation between microbial findings from superficial swabs and deep tissue specimens when they were delivered to the microbiology laboratory immediately after collection.
\end{abstract}

Key words: diabetic foot, infection, etiology

\section{Introduction}

Diabetes mellitus is a chronic disorder and a major public health problem. Infections are a common

Revision received: April 01, 2013

Accepted: June 26, 2013 
complication in diabetic patients, and they are usually more severe than infections in nondiabetic patients. Foot infections are among the most common complications in diabetic patients and a common case of morbidity and mortality. Twenty-five percent of all diabetics develop severe foot or leg problems and foot infections account for about $20 \%$ of all hospital admissions in diabetics. At least $50 \%$ of all non-traumatic lower extremity amputations occurring in the United States are performed on diabetics [1].

There are a number of predisposing factors, which determine the severity of this complication: impaired immunologic response, peripheral neuropathy, and peripheral arterial disease. Depending on the control of diabetes, these factors can be present in varying degrees [2]. In cases of poor control, an infection can develop, spread rapidly, and produce significant and irreversible tissue damage, resulting in a high rate of amputations [3].

Diabetic foot infection requires the attention of a multi-disciplinary foot-care team. According to guidelines, the following issues need consideration:

1) Should uninfected diabetic ulcers be treated with antibiotics?

2) If antibiotic therapy is necessary for various type of soft tissue and bone infections, what is the optimal treatment regimen regarding therapeutic agents, route of administration and duration?

3) How could a simple cost-effective algorithm for diagnosis and treatment of infection be designed and eventually introduced in clinical practice? [2].

The aim of our prospective study was to investigate the spectrum and susceptibility of microorganisms isolated from diabetic foot ulcers in patients with poorly controlled diabetes, and compare microbial findings of specimens collected superficially and from deep tissues, and eventually propose a cost-effective empiric therapy of diabetic foot infection.

\section{Material and Methods}

The study included 19 patients ( 11 females and 8 males, mean age 63.9 years, (range $47-86$ years) with diabetes type 1 and 2 and clinical signs of infection. They were all treated in septic and vascular surgery wards of the University Hospital in Pleven between February 1, 2012 and September 30, 2012. All the patients in the study group had diabetic polyneuropathy confirmed by the $10 \mathrm{~g}$-monofilament test [4]. All the patients had poorly controlled diabetes, as was shown by mid-values of serum glucose at admission 14.08 (range $4.4-47 \mathrm{mmol} / \mathrm{l}$ ) and mid-values of glycated hemoglobin - 8.96\% (range 7.139.96\%).

All the patients had limb-threatening infections, presenting with at least one of the following criteria of Robert et al.: cellulites $>2$ $\mathrm{cm}$, edema, pain and lymphangitis, drainage and odor, and systemic signs as hypotension, fever and ischemic changes [5].

Nine patients had stage 3 infection, seven had stage 4 , and three had stage 5 infection according to the Wagner scale [6]. These stages corresponded to III B and III D stage of Texas University Diabetic Foot Scale [7].

Swabs from non-debrided wounds and biopsy samples from soft tissues were collected from each patient. Both types of samples were immediately delivered to the microbiology laboratory. Dressings were done twice a day, and surgical interventions were performed whenever needed for cellulites. Amputations were performed on patients with gangrene.

Specimens were inoculated on blood agar (5\% sheep blood), Levine agar, Schaedler agar and into thioglycolate broth for isolation of aerobic and anaerobic bacteria. Identification and susceptibility testing of the isolated microorganisms were performed by conventional methods, VITEK 2 and mini API Systems (bioMerieux, France).

\section{Results}

A total of 88 bacterial isolates were cultured, comprising 56 clinical strains (Table 1). Grampositive aerobic bacteria were predominant among the strains isolated - 30 strains $(53.57 \%)$, followed by Gram-negative aerobic bacteria - 15 strains $(26.78 \%)$, and anaerobic bacteria -11 strains (19.65\%). Staphylococcus aureus was the most common organism detected (10 strains), followed by Enterococcus species (7 strains), Escherichia coli (7strains), Bacteroides species (6 strains) and Streptococcus agalactiae (4 strains). Various other organisms were isolated but their number was small.

In only two cases the infection was monobacterial, caused by E.coli in one case, and by Pseudomonas aeruginosa, in another. In 17 patients $(89.47 \%)$, the infections were polymicrobial: caused by two organisms -5 
_ Iliev S. et al. Etiology of diabetic foot infection in patients with poorly controlled diabetes

Table 1. Distribution of clinical strains isolated from diabetes foot ulcers

\begin{tabular}{ll}
\hline Microorganism & $\begin{array}{l}\text { Number of } \\
\text { isolated strains }\end{array}$ \\
\hline Total Gram - positive bacteria & $\mathbf{3 0} \mathbf{( 5 3 . 5 7 \% )}$ \\
\hline S. aureus & 10 \\
\hline S. epidermidis & 5 \\
\hline S. agalactiae & 4 \\
\hline E. faecalis & 6 \\
\hline E. fa ecium & 1 \\
\hline Corynebacterium spp. & 2 \\
\hline S. viridans & 1 \\
\hline Bacillus spp. & 1 \\
\hline Total: & \\
\hline Total Gram - negative bacteria & $\mathbf{1 5} \mathbf{( 2 6 . 7 8 \% )}$ \\
\hline E. coli & 7 \\
\hline E. cloacae & 2 \\
\hline K. pneumoniae & 1 \\
\hline K. oxytoca & 1 \\
\hline K. ornithinolytica & 1 \\
\hline P. mirabilis & 1 \\
\hline M. morganii & 1 \\
\hline P. aeruginosa & 1 \\
\hline Total: & 1 \\
\hline Non- sporeforming and & 1 \\
\hline sporeforming anaerobic bacteria & 1 \\
\hline B. fragilis & 1 \\
\hline Bact. ovatus & 1 \\
\hline Peptostreptococcus asaccha rolyticus & 1 \\
\hline Veil lonella spp. & 1 \\
\hline Peptostreptococc us anaerobius & 1 \\
\hline Totevtridium spp. & 1 \\
\hline
\end{tabular}

(26.31\%), by 3 organisms $-11(57.89 \%)$ and by 4 organisms - $1(5.26 \%)$ (Figure 1). Mixed infections, caused by aerobic and anaerobic bacteria were found in 9 patients $(47.3 \%)$. In 15 patients $(78.94 \%)$ there was a coincidence of bacterial findings in superficial and deep tissue samples. The findings matched totally in 9 of them $(47.36 \%)$, and in 6 patients $(31.57 \%)$ the findings matched partially. In 4 cases $(11.06 \%)$ there was no coincidence at all (Figure 2).

Isolated strains had a high-degree susceptibility to antimicrobials. None of the isolated strains was a typical causative agent of nosocomial infections. S.aureus strains were resistant only to penicillin G. S.agalactiae isolates were susceptible to all recommended antibiotics. E.coli strains were resistant to ampicillin, amoxicillin, first generation cephalosporins and trimethoprim/sulfamethoxazole. Klebsiella species were resistant to ampicillin, amoxicillin and first generation cephalosporins. Only two of all isolated Grampositive and Gram-negative aerobic bacteria were resistant to ciprofloxacin. 


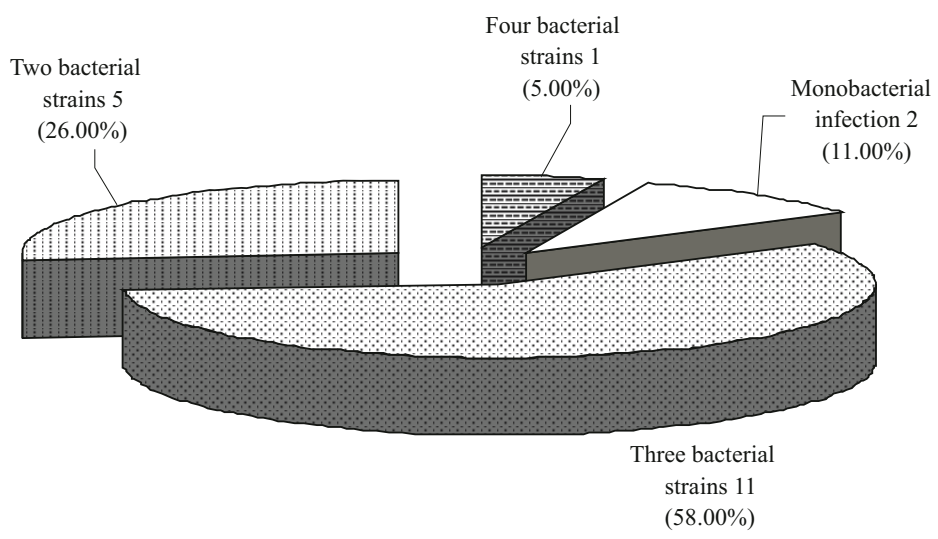

Figure 1. Relative share of monobacterial and polymicrobial infections

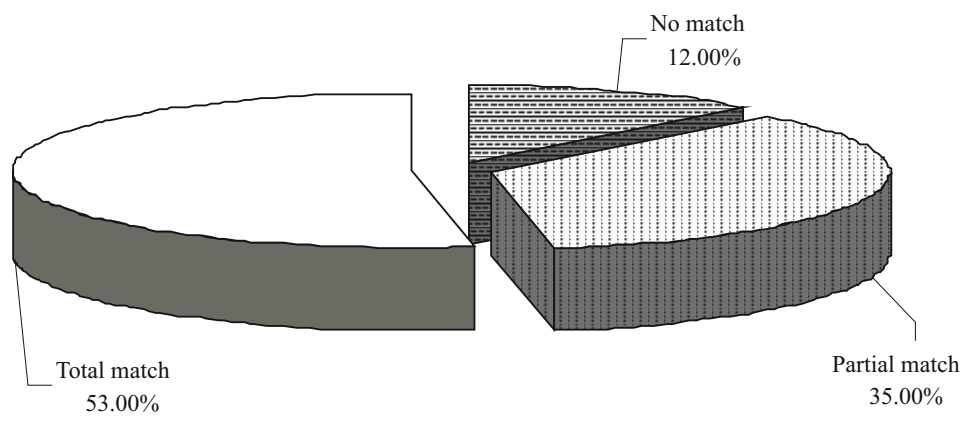

Figure 2. Correlation between superficial and deep sample results

\section{Discussion}

The organisms, isolated in cases of diabetic foot infections are partly related to the severity of the underlying disease. The diabetic foot infections have been divided into two groups: mild nonlimb threatening infections and more severe limb-threatening infections. Previous studies have provided evidence that in mild non-limb threatening acute infections the causative organism is mostly S.aureus and in half of the cases, infections are monobacterial $[8,9]$. Severe limb-threatening infections are usually polymicrobial [10].

Our patients were with severe limbthreatening infections, and a monobacterial infection was identified in two cases only. This finding is in support of Hunt's statement, according to which foot infections in diabetes are rarely caused by a single organism [11].

In our study, about $90 \%$ of severe infections were polymicrobial, and mixed aerobic/ anaerobic infections were found in about half of the cases. This is in accordance with the findings of other studies, in which anaerobes are isolated from $40 \%$ to $80 \%$ of patients with severe or advanced disease. They are usually present in cultures yielding multiple organisms [9, 10]. Common anaerobic isolates include anaerobic streptococci, Bacteroides species and Clostridium species [10]. According to Forbes et al., most anaerobic infections involve a mixture of anaerobic and facultative anaerobic organisms, so that it is difficult to establish the extent to which a particular anaerobic species contributes to infection. In addition, as ubiquitous members of the normal flora, anaerobic organisms often contaminate samples. For these reasons, assigning clinical significance to anaerobic bacteria isolated in the laboratory is important, although often difficult to achieve [12]. The strains we isolated do not belong to the normal skin flora. This makes us assume that they are clinically significant etiologic agents. 
Aerobes accounted for about $80 \%$ from all the strains we isolated. Aerobic Gram-positive cocci were predominant. S.aureus was most commonly isolated pathogen, followed by Enterococcus species and S.agalactiae. All three pathogens accounted for about two-thirds of the isolates. These finding are in agreement with results reported by other investigators $[13,14]$.

In the present study we isolated S.epidermidis from the ulcers of five patients and Corynebacterium spp. from the ulcers of two patients. The pathogenic role of coagulasenegative staphylococci and corynebacteria is often difficult to define, particularly when these organisms are cultured along with more typical pathogens. These organisms can be assumed to be skin contaminants, rather than pathogens (unless they are isolated in pure culture, or when a patient does not respond to therapy not oriented to these organisms) [9]. However, according to Lipsky and coworkers and Bessman and coworkers [2, 15], the impaired host defenses around necrotic soft tissue or bone may allow low-virulence colonizers such as coagulasenegative staphylococci and corynebacteria to assume a pathogenic role.

According to literature data, Enterobacteriaceae account for 24 to $27 \%$ of the organisms isolated. Common isolates include Proteus, Klebsiella and Enterobacter species, Morganella morganii and E.coli. Pseudomonas and Acinetobacter species are common contaminants in specimens from ulcers or open draining lesions but are seldom isolated from deep tissue cultures [16, 17]. In our study Enterobacteriaceae accounted for about $21.0 \%$ of all isolates. In the case of isolation of P.aeruginosa, the strain was isolated from both superficial and deep tissues.

The best method to obtain wound or tissue cultures from diabetic foot infections is still debatable [18]. Most authors agree that results from microbiological research of specimens from superficial wounds are not significant and should not be taken into account, while other investigators use sterile swabs and samples from

\section{References}

1. Cunha BA. Antibiotic selection for diabetic foot infections: a review. J Foot Ankle Surg. 2000;39(4):253-7. superficial wounds with good results $[19,20]$. One of our goals was exactly that: to compare results from specimens obtained from superficial and deep tissues. All samples investigated were delivered to the laboratory immediately after collection and were cultured as soon as possible (10 to 15 minutes following delivery). In more than two-thirds of the cases we studied there was coincidence of results from both cultures. We believe these results are attributable to the following circumstances: 1) Immediate transportation and proceeding of samples and 2) It is known, that even the strict anaerobes are somewhat aerotolerant and are resistant to oxygen for about 10-20 minutes. The fact, that we isolated obligate anaerobes from superficial wounds in 6 patients supports this statement. The same pathogens were isolated from deep tissues as well.

The strains isolated in our study were susceptible to commonly used antimicrobials for treatment of diabetic foot infections. These results made it possible to apply antimicrobial treatment regimens, taking into consideration the latest guidelines for treatment of diabetic foot infections [10], the resistance of the isolated strains and the cost of treatment.

The correlation between etiology of infections, resistance of isolated strains to antimicrobial agents, antibiotics of choice and their price, suggest that in our clinics the most preferable group antimicrobials should be fluoroquinolones in polymicrobial infections, and lincosamides in infections caused by Grampositive organisms alone.

\section{Conclusions}

Most diabetic foot infections are polymicrobial, caused by association of two or three microbial species. In half of the cases the infection is mixed. There is a good correlation in microbial findings from superficial swabs and deep tissue specimens when they are taken to a microbiology laboratory immediately after collection.
2. Lipsky BA, Berendt AR, Deery HG, Embil JM, Joseph WS, Karchmer AW, et al. Diagnosis and treatment of diabetic foot infections. Clin Infect Dis. 2004;39:885-910.

3. Caputo GM. The rational use of antimicrobial agents in diabetic foot infection. In: Boulton AJM, 
Connor H, Cavanagh PR, editors. The Foot in Diabetes, 3rd ed. Chichester: Wiley and Sons; 1994. p. 143-51.

4. Mayfield JA, Sugarman JR. The use of the Semmes-Weinstein monofilament and other threshold tests for preventing foot ulceration and amputation in persons with diabetes. J Fam Prac. 2000;49(Supp 111):S17-29.

5. Frykberg RG, Zgonis T, Armstrong DG, Driver VR, Giurini JM, Kravitz SR et al. Diabetic foot disorders. A clinical practice guideline (2006 revision). J Foot Ankle Surg. 2006;45(Suppl 5):S1-66.

6. Wagner FW Jr. The diabetic foot. Orthopedics. 1987;10:63-72.

7. Oyibo SO, Jude EB, Tarawneh I, Nguyen HC, Harkless LB, Boulton AJ. A comparison of two diabetic foot ulcers classification systems: the Wagner and the University of Texas wound classification systems. Diabetic Care. 2001; 24(1):84-8.

8. Caputo GM, Gavanagh PR, Ulbrecht JS, Gibbson GW, Krachmer AW. Assessment and management of foot disease in patients with diabetes. N Engl J Med. 1994;331:854-60.

9. Ge Y, Mac Donald D, Hait H, Lipsky B, Zasloff M, Holroyd K. Microbiological profile of infected diabetic foot ulcers. Diabet Med. 2002; 19(12):1032-4.

10. Nolan RL, Chapman SW. Bone and joint infection. In: Betts RF, Chapman SW, Penn RL, editors. Reese and Betts' A practical approach to infectious diseases. Philadelphia, PA: Lippincott Williams \& Wilkins; 2003.p. 127-173.

11. Hunt JA. Foot infections in diabetes are rarely due to a single organism. Diabet Med.1992;9(8):74952.
12. Forbes BA, Sahm DF, Weissfeld AS.Anaerobic Bacteriology. Overview and general consideration. In: Bailey \& Scott's Diagnostic Microbiology, 11th ed. St. Louis, MI: Mosby; 2002. p.511-9.

13. Lipsky BA, Pecorado RE, Wheat LJ. The diabetic foot. Soft tissue and bone infection. Infect Dis Clin North Am. 1990;4(3):409-32.

14. El-Tahawy AT. Bacteriology of diabetic foot. Saudi Med. 2000;21(4):344-7.

15. Bessman AN, Geiger PJ, Canawati H. Prevalence of Corynebacteria in diabetic foot infections. Diabetic care. 1992;15(11):1531-3.

16. Wheat LJ, Allen SD, Henry M, Kernek CB, Siders JA, Kuebler T, et al. Diabetic foot infections. Bacteriological analysis. Arch Intern Med. 1986; 146(10):1935-40.

17. Sapico FL, Witte JL, Canavati HN, Montgomerie JZ, Besseman AN. The infected foot of the diabetic patient: quantitative microbiology and analysis of clinical features. Rev Infect Dis. 1984;6 (Suppl 1):S171-6.

18. Pellizzer G, Strazzabosco M, Presi S, Furlan F, Lora L, Benedetti P, et al. Deep tissue biopsy vs. superficial culture monitoring in the microbiological assessment of limb-threatening diabetic foot infection. Diabet Med. 2001; 18(10):822-7.

19. Ihsan Edan AA. Bacterial wound infections in diabetic patients and their therapeutic implications. Med Pract Rev. 2010;1(2):12-5.

20. Anandi C, Alaguraja D, Natarajan V, Ramanathan M, Subramaniam CS. Bacteriology of diabetic foot lesions. Indian J Med Microbiol. 2004; 22(3):173-8. 